\title{
Comparative analysis of outcomes following craniotomy and expanded endoscopic endonasal transsphenoidal resection of craniopharyngioma and related tumors: a single-institution study
}

\author{
Sunil Jeswani, MD, ${ }^{1}$ Miriam Nuño, PhD, ${ }^{1}$ Arthur Wu, MD, ${ }^{2}$ Vivien Bonert, MD, ${ }^{3}$ \\ John D. Carmichael, MD, ${ }^{3}$ Keith L. Black, MD, ${ }^{1}$ Ray Chu, MD, ${ }^{1}$ Wesley King, MD, ${ }^{1}$ and \\ Adam N. Mamelak, MD'
}

Departments of ${ }^{1}$ Neurosurgery, ${ }^{2}$ Otorhinolaryngology, and ${ }^{3}$ Endocrinology, Cedars-Sinai Medical Center, Los Angeles, California

OBJECTIVE Craniopharyngiomas and similar midline suprasellar tumors have traditionally been resected via transcranial approaches. More recently, expanded endoscopic endonasal transsphenoidal approaches have gained interest. Surgeons have advocated for both approaches, and at present there is no consensus whether one approach is superior to the other. The authors therefore compared surgical outcomes between craniotomy and endoscopic endonasal transsphenoidal surgery (EETS) for suprasellar tumors treated at their institution.

METHODS A retrospective review of patients undergoing resection of suprasellar lesions at Cedars-Sinai Medical Center between 2000 and 2013 was performed. Patients harboring suspected craniopharyngioma were selected for extensive review. Other pathologies or predominantly intrasellar masses were excluded. Cases were separated into 2 groups, based on the surgical approach taken. One group underwent EETS and the other cohort underwent craniotomy. Patient demographic data, presenting symptoms, and previous therapies were tabulated. Preoperative and postoperative tumor volume was calculated for each case based on MRI. Student t-test and the chi-square test were used to evaluate differences in patient demographics, tumor characteristics, and outcomes between the 2 cohorts. To assess for selection bias, 3 neurosurgeons who did not perform the surgeries reviewed the preoperative imaging studies and clinical data for each patient in blinded fashion and indicated his/her preferred approach. These data were subject to concordance analysis using Cohen's kappa test to determine if factors other than surgeon preference influenced the choice of surgical approach.

RESULTS Complete data were available for 53 surgeries; 19 cases were treated via EETS, and 34 were treated via craniotomy. Patient demographic data, preoperative symptoms, and tumor characteristics were similar between the 2 cohorts, except that fewer operations for recurrent tumor were observed in the craniotomy cohort compared with EETS ( $17.6 \%$ vs $42.1 \%, p=0.05)$. The extent of resection was similar between the 2 groups $(85.6 \%$ EETS vs $90.7 \%$ craniotomy, $p=0.77$ ). An increased rate of cranial nerve injury was noted in the craniotomy group ( $0 \%$ EETS vs $23.5 \%$ craniotomy, $p=0.04)$. Postoperative CSF leak rate was higher in the EETS group ( $26.3 \%$ EETS vs $0 \%$ craniotomy, $p=0.004)$. The progression-free survival curves (log-rank $p=0.99)$ and recurrence rates $(21.1 \%$ EETS vs $23.5 \%$ craniotomy, $p=$ 1.00) were similar between the 2 groups. Concordance analysis of cases reviewed by 3 neurosurgeons indicated that individual surgeon preference was the only factor that determined surgical approach (kappa coefficient $-0.039, p=0.762$ )

CONCLUSIONS Surgical outcomes were similar for tumors resected via craniotomy or EETS, except that more CSF leaks occurred in the EETS cohort, whereas more neurological injuries occurred in the craniotomy cohort. Surgical approach appears to mostly reflect surgeon preference rather than specific tumor characteristics. These data support the view that EETS is a viable alternative to craniotomy, providing a similar extent of resection with less neurological injury. http://thejns.org/doi/abs/10.3171/2015.3.JNS142254

KEY WORDS craniopharyngioma; suprasellar; endoscopic; transsphenoidal; outcomes; complications; skull base

ABBREVIATIONS DI = diabetes insipidus; EETS = endoscopic endonasal transsphenoidal surgery; EOR = extent of resection; GTR = gross-total resection; IQR = interquartile range; $\mathrm{PFS}=$ progression-free survival; $\mathrm{RCT}=$ randomized clinical trial.

SUBMITTED September 29, 2014. ACCEPTED March 18, 2015.

INCLUDE WHEN CITING Published online September 11, 2015; DOI: 10.3171/2015.3.JNS142254. 
$\mathrm{M}$ IDLINE suprasellar tumors represent a unique surgical challenge for neurosurgeons. A variety of growths occur in this space, including craniopharyngioma, meningioma, germinoma, metastasis, pituitary adenoma, lymphoma, and glioma. Resection has remained a mainstay of treatment for many of these tumors, although significant debate exists as to the benefit of attempted gross-total resection (GTR). $.5,9,12,13,19,27,41,48,49,52$

Transcranial approaches have been traditionally used to remove suprasellar masses. Pterional, bifrontal, and subfrontal approaches have all been described. These procedures can require a significant amount of brain retraction, which may result in edema, contusion, or venous compromise. ${ }^{14,38,45,47,53}$ In addition, the dissection often requires manipulation of neurovascular structures such as the internal carotid artery and its branches, as well as the cranial nerves, including the optic apparatus..$^{29,32,35,38,52,53}$ Moreover, direct visualization and/or dissection of the tumor may be difficult due to its location below the optic nerves, filling of the third ventricle, or extension into the posterior fossa. Not surprisingly, complications involving injury to these neurovascular structures via these approaches have been reported. .,14,38,45,47,53 $^{2}$

In recent years, expanded endoscopic endonasal transsphenoidal surgery (EETS) has become increasingly popular for access to the midline suprasellar space. . $^{2,47,16,18,36}$ Via transplanum extensions, this approach provides direct access to the infrachiasmatic, olfactory, and subfrontal regions; and via transclival extensions, to the prepontine and perimesencephalic regions. The direct visualization to the skull base afforded by this approach minimizes brain retraction and manipulation of neurovascular structures, and provides a wide operative field compared with standard microscope-based transsphenoidal approaches. $3,15,16,24,28,31$

Although both approaches have their advantages and advocates, there is no clear consensus whether one is superior to the other. The most direct way to resolve this issue would be to perform a comparison of surgical outcomes between these 2 approaches. Several authors have documented their experience with endoscopic endonasal approaches for suprasellar lesions., ${ }^{2,7,16,17,30,31,34}$ Similarly, there are an abundant number of reports of outcomes following transcranial approaches but no series directly comparing these approaches in a single- or multiinstitutional cohort. One systematic review has compared EETS to cranial approaches based on reported case series. ${ }^{28} \mathrm{Be}-$ cause the goals, such as the aggressiveness of resection, may vary among institutions, it is difficult to compare outcomes in a systematic review of this nature.

To better address this issue, we compared the surgical outcomes, including extent of resection (EOR), complication rate, and progression-free survival (PFS), between the 2 approaches for cases treated at a single institution.

\section{Methods}

All patients with midline suprasellar lesions that were resected at Cedars-Sinai Medical Center between January 2000 and March 2013 were identified by retrospective review of the Department of Pathology surgical case log. Patients with histologically verified pathologies of cranio- pharyngioma, pituicytoma, and xanthogranuloma were included in this review. Meningioma, pituitary adenoma, glioma, and other nonstalk-based lesions were excluded, as were stalk-based lesions requiring only biopsy, such as lymphoma, hypophysitis, or germinoma. These inclusion and exclusion criteria resulted in a subset of tumors of similar size and operative requirements, with similar operative techniques and expected goals of surgery. For each case, the patient's medical chart was reviewed. Demographic information including patient age, sex, presenting symptoms, hormonal status, visual field examination, and previous therapies were recorded.

All patients who underwent operation before the year 2000 were excluded from this study to let the data reflect more current techniques and approaches, as well as a more unified institutional philosophy regarding the goals of surgery. Additionally, patients with primarily intrasellar tumors were not included in this study, because the aim of the study was to compare operative techniques for midline suprasellar/third ventricular lesions. Xanthogranuloma and pituicytoma cases were included because these lesions appear radiographically and clinically similar to craniopharyngioma, were presumed to represent craniopharyngioma prior to surgery, and the surgical strategy used mimicked that for craniopharyngioma. Surgeons only became aware of the alternate pathological type on postoperative histological examination. Therefore, the expected surgical morbidities and outcomes in these cases are similar enough to those of craniopharyngioma to warrant inclusion. Finally, cases with insufficient or incomplete records were also excluded.

The patients included in this study were arranged into 2 groups: those who underwent a craniotomy (including bifrontal, pterional, orbitozygomatic, or transcallosal), and those who underwent EETS. Because the primary objective of the analysis was to determine if either method was associated with more complications, more complete resection, or improved survival prognosis, the analysis focused primarily on surgical cases rather than individual patients. Since this study focused on comparing surgical procedures, patients who underwent reoperation for recurrence of their tumor, but via a different approach from that of the index surgery, were designated to both groups. For example, a patient who initially underwent craniotomy and later underwent EETS for a recurrence was evaluated for complications, EOR, and survival in both the craniotomy and EETS groups.

For each operative case, tumor volumes were measured from a pre- and postoperative MRI scan, using the line measurement tool on our picture archiving and communication system (PACS) station (GE Healthcare). Preoperative MRI scans were always obtained within 2 weeks prior to surgery, whereas postoperative scans were obtained either 1-2 days or 3 months after surgery, depending on surgeon preference and clinical indication. Tumor volumes were computed using the following equation: $\mathrm{Tu}$ mor volume $=(\mathrm{A} \times \mathrm{B} \times \mathrm{C}) / 2$, where $\mathrm{A}, \mathrm{B}$, and $\mathrm{C}$ represent the dimensions of the tumor in 3 orthogonal planes. This equation assumes that the shape of the lesion approximates roughly a sphere. Although this measurement is only a reasonable estimate rather than an exact measure 
of tumor volume, it provided adequate assessment of the EOR with some degree of quantitation. All tumor volumes were recorded in units of cubic centimeters. The EOR for each case was computed by the following equation: EOR $=1-$ postoperative volume/preoperative volume.

Additional characteristics of the tumor were also recorded, including the consistency of the tumor (solid vs cystic), as indicated by the surgeon's operative note and the lesion's radiographic appearance. Tumors were classified based on their location in relation to the infundibular stalk. Using the classification scheme proposed by Kassam et al. ${ }^{25}$ lesions located primarily anterior to the stalk were classified as Type I, lesions located intrinsic to the stalk were designated as Type II, and lesions posterior to the stalk were classified as Type III. The pathologies for all cases were recorded. Craniopharyngiomas were divided into adamantinomatous or papillary subtypes.

For each surgery, intraoperative and postoperative complications were tabulated. These included vascular, neurological, hormonal, and CSF leak complications. Follow-up data for each case were also tabulated, including whether the patient underwent reoperation or radiation for recurrent or progressive tumor, length of PFS, and time of last follow-up. The PFS was calculated as the time from initial surgery to radiation and/or additional surgery for MRI-documented evidence of tumor growth. This included both growth of existing residual disease and recurrence of disease in a patient with no radiographic evidence of disease on prior MR images. For cases with no progression or recurrence (i.e., censored), PFS was the same as the length of time from initial surgery to last follow-up.

A significant concern in a retrospective review of this nature is that selection bias influenced the surgical approach and that outcomes are reflective of this bias. For example, tumors with a more solid component might tend to be selected for craniotomy, whereas more cystic tumors would be selected for EETS. In turn this could affect results, such as EOR. To address this potential confounding factor, 3 neurosurgeons who were experienced in tumor resection ( $>10$ years clinical practice) and who were not involved in the cases were asked to evaluate the preoperative images and clinical data for each patient, and to select the surgical approach he or she would prefer for that case. The neurosurgeons were blinded to each other, to the actual surgeon or patient identifiers, and to any information about outcomes. These data were tabulated, compared with the actual procedure performed, and subjected to concordance analysis. In the absence of a randomized clinical trial (RCT), these data are useful to determine if certain tumors were always preferentially selected for craniotomy or EETS, or if the surgical approach was principally attributable to surgeon preference.

Statistical analysis for differences in demographic variables, EOR, complication rates, types of complications, PFS, and recurrence rate were calculated between craniotomy and EETS cases. Descriptive statistics were reported for all patients as well as for cohorts classified according to treatment group. Continuous variables were described using means, medians, and interquartile ranges (IQRs), whereas categorical variables were reported in terms of frequencies. Univariate comparisons were conducted us- ing Student t-test, chi-square, and Fisher's exact tests where appropriate. The Kaplan-Meier estimation method was used to obtain PFS functions for patients treated with craniotomy versus EETS surgery, and the curves were compared using the log-rank test. Cohen's kappa test was used to evaluate concordance between surgical approaches among surgeons. A p value $\leq 0.05$ was considered to be statistically significant. All statistical analyses were conducted in SAS 9.2 (SAS Institute).

\section{Results}

A total of 67 patients treated between 2000 and 2013 were identified. Cases treated prior to 2000, those with incomplete records, and those involving primarily intrasellar tumors were excluded, leaving 46 patients comprising 53 operative cases. Nineteen (35.8\%) surgeries were performed via the EETS approach, whereas 34 (64.2\%) were performed via a craniotomy. Among the 19 EETS procedures, $11(57.9 \%)$ were initial operations and 8 $(42.1 \%)$ treated a recurrent or progressive tumor that had previously been resected via an EETS or craniotomy. Of the 34 craniotomy cases, $28(82.4 \%)$ were deemed initial operations and $6(17.6 \%)$ procedures treated cases of recurrent or progressive disease. The proportion of first-time operations between the 2 groups differed, with a greater percentage of first-time resections performed in the craniotomy group $(82.4 \%$ vs $57.9 \%$, $\mathrm{p}=0.05)$.

The mean age at surgery for the entire cohort $(n=53)$ treated with either a craniotomy or EETS procedure was 45.2 years, with an IQR of 38-59 years (Table 1). The average age among craniotomy (45.3 years) and EETS (45 years) patients was comparable $(p=0.96)$. Fewer female patients were treated with a craniotomy compared with EETS $(44.1 \%$ vs $52.65 \%, p=0.55)$. A description of preoperative symptoms showed that visual disturbances (54.7\%) were most commonly observed, followed by endocrinopathy $(41.5 \%)$, neurological symptoms $(32.1 \%)$, and headaches $(26.4 \%)$. The rates of preoperative symptoms were comparable between cases treated with a craniotomy and EETS, with the exception of a moderate difference in neurological symptoms (craniotomy: $41.2 \%$, EETS: $15.8 \%$; $p$ $=0.07$ ). Because preoperative symptoms encompassed a wide spectrum of conditions, Table 2 provides a detailed summary of the presenting signs and symptoms in each surgical group.

Table 3 demonstrates histological characteristics in the 2 groups. All tumors were midline suprasellar/third ventricular tumors, with the overwhelming majority (92.5\%) of cases comprising craniopharyngioma. Other pathological types were pituicytoma and xanthogranuloma. Among the craniopharyngiomas, the frequency of subtypes based on histological characteristics (adamantinomatous vs papillary) and infundibular classification are also listed in Table 3. No significant difference in tumor pathology or consistency was seen between the 2 cohorts. Among craniopharyngiomas, no significant difference was seen in the distribution of infundibular class between the 2 groups. The preoperative tumor volume was similar between the 2 groups $\left(9.5 \mathrm{~cm}^{3}\right.$ vs $\left.9.0 \mathrm{~cm}^{3}, \mathrm{p}=0.84\right)$.

Within the EETS group, the predominant surgical ap- 
TABLE 1. Characteristics and symptoms of patients treated with craniotomy and expanded EETS*

\begin{tabular}{|c|c|c|c|c|}
\hline Variable & All Cases & Craniotomy & EETS & $p$ Value \\
\hline No. of cases & 53 & $34(64.2)$ & $19(35.8)$ & \\
\hline Age in yrs & & & & 0.96 \\
\hline Mean (SD) & $45.2(18.7)$ & $45.3(19.8)$ & $45(17.0)$ & \\
\hline Median (IQR) & $48(38-59)$ & $47(34-61)$ & $49(38-57)$ & \\
\hline Female sex & $25(47.2)$ & $15(44.1)$ & $10(52.6)$ & 0.55 \\
\hline \multicolumn{5}{|l|}{ Preop symptoms } \\
\hline Visual disturbances & $29(54.7)$ & $18(52.9)$ & $11(57.9)$ & 0.73 \\
\hline Headaches & $14(26.4)$ & $9(26.5)$ & $5(26.3)$ & 0.99 \\
\hline Endocrine disturbances & $22(41.5)$ & $14(41.2)$ & $8(42.1)$ & 0.95 \\
\hline Neurological symptoms & $17(32.1)$ & $14(41.2)$ & $3(15.8)$ & 0.07 \\
\hline First-time op & $39(73.6)$ & $28(82.4)$ & $11(57.9)$ & 0.05 \\
\hline
\end{tabular}

* Unless otherwise specified, values are expressed as the number of cases (\%).

proach was a transsphenoidal and transplanum approach. In one case a combined transplanum and transclival approach was used. In another case early in the series, a sublabial approach was used. In the craniotomy group, the surgical approach varied significantly depending on the anatomical location of the tumor and surgeon preference. The approaches included pterional (35.3\%), bifrontal (35.3\%), supraorbital keyhole craniotomy (8.8\%), interhemispheric transcallosal (8.8\%), transventricular (5.9\%), orbitozygomatic $(2.9 \%)$, and subtemporal $(2.9 \%)$.

The mean EOR for all cases within each group is summarized in Table 4. Given that reoperations performed for recurrent or progressive tumors may entail more challenging resections than first-time cases due to more aggressive pathology, scarring, and difficult anatomical location,

TABLE 2. Presenting signs and symptoms in patients treated with craniotomy and expanded EETS

\begin{tabular}{lcc}
\hline \multirow{2}{*}{ Signs \& Symptoms } & \multicolumn{2}{c}{ No. of Cases (\%) } \\
\cline { 2 - 3 } No. in cohort & Craniotomy & EETS \\
\hline Visual disturbances & $34(64.2)$ & $19(35.8)$ \\
\hline Headaches & $18(52.9)$ & $11(57.9)$ \\
\hline Weight gain/loss & $9(26.4)$ & $5(26.3)$ \\
\hline Hypogonadism & $1(2.9)$ & $2(10.5)$ \\
\hline Memory loss & $1(2.9)$ & $3(15.8)$ \\
\hline Lethargy & $6(17.6)$ & $1(5.3)$ \\
\hline Dizziness/vertigo & $0(0)$ & $2(10.5)$ \\
\hline Orthostatic hypotension & $2(5.9)$ & $1(5.3)$ \\
\hline Fatigue & $0(0)$ & $1(5.3)$ \\
\hline Gait instability & $4(11.8)$ & $0(0)$ \\
\hline Emotional disturbances & $3(8.8)$ & $0(0)$ \\
\hline Altered mental status & $1(2.9)$ & $0(0)$ \\
\hline Galactorrhea & $3(8.8)$ & $0(0)$ \\
\hline Failure to thrive & $1(2.9)$ & $0(0)$ \\
\hline Excessive thirst & $3(8.8)$ & $1(5.3)$ \\
\hline Polyuria & $1(2.9)$ & $0(0)$ \\
\hline Incontinence & $1(2.9)$ & $0(0)$ \\
\hline
\end{tabular}

EOR was also subdivided and evaluated separately for first-time cases and reoperation cases. No significant difference was found in the EOR between the 2 cohorts, both overall $(90.7 \%$ vs $85.6 \%, p=0.77)$ and separately for firsttime $(\mathrm{p}=0.43)$ and redo operations $(\mathrm{p}=0.36)$.

New endocrine deficits were the most frequent complications, representing $50.9 \%$ of all complications, followed by cranial nerve injuries (including visual deficits), representing $15.1 \%$ of all complications. Comparisons of specific complication rates between the craniotomy and EETS groups are depicted in Table 5. The most commonly encountered complications in both groups were panhypopituitarism and diabetes insipidus (DI), occurring with similar frequency in both groups $(38.2 \%$ vs $42.1 \%$ for panhypopituitarism, and $52.9 \%$ vs $31.6 \%$ for DI).

The complications were grouped into endocrinological complications, cranial nerve injury including optic nerve injury, hydrocephalus/hygroma, stroke/hemorrhage, CSF leak, death, and other (Table 6). The incidence of cranial nerve injury including visual deficit was significantly higher in the craniotomy group $(23.5 \%$ vs $0 \%, \mathrm{p}=0.04)$. These included injuries to the optic, oculomotor, trochlear, olfactory, and frontalis branch of the facial nerve. The incidence of CSF leaks was significantly higher in the EETS group ( $0 \%$ craniotomy vs $26.3 \%$ EETS, $p=0.004)$. Other complications, including hydrocephalus $(\mathrm{p}=0.69)$, stroke $(\mathrm{p}=1.00)$, and death $(\mathrm{p}=1.00)$ were similar between the 2 groups.

The mean follow-up time in the craniotomy group was 1049 days. The mean follow-up time in the EETS group was 1022 days $(p=0.80)$. The PFS times as well as the rates of reoperation/radiation for recurrent or progressive tumor are shown in Table 7. Due to the fact that reoperation cases may have an increased likelihood of more aggressive and/or difficult-to-resect tumors, the PFS in this group may be different than in cases in which a first-time operation was performed. Therefore, the PFS for first-time and reoperation cases was calculated separately. The mean PFS times were similar between the 2 cohorts (760 vs 780 days, $p=0.78)$, including between the first-time operation $(\mathrm{p}=0.91)$ and reoperation $(\mathrm{p}=0.27)$ subcohorts. In addition, Kaplan-Meier curves were constructed for the PFS for both cohorts (Fig. 1). There was no significant differ- 
TABLE 3. Characteristics and histological findings in tumors resected via craniotomy and expanded EETS*

\begin{tabular}{|c|c|c|c|c|}
\hline Variable & All Surgeries & Craniotomy & EETS & $p$ Value \\
\hline No. of cases & 53 & $34(64.2)$ & $19(35.8)$ & \\
\hline Pituicytoma & $3(5.7)$ & $1(2.9)$ & $2(10.5)$ & 0.29 \\
\hline Xanthogranuloma & $1(1.9)$ & $0(0)$ & $1(5.3)$ & 0.36 \\
\hline Craniopharyngioma & $49(92.5)$ & $33(97.0)$ & $16(84.2)$ & 0.13 \\
\hline Adamantinomatous subtype & $34(69.4)$ & $23(69.7)$ & $11(68.8)$ & 1.00 \\
\hline Papillary subtype & $14(28.6)$ & $9(27.3)$ & $5(31.3)$ & 1.00 \\
\hline Infundibular Type I & $7(14.3)$ & $5(15.2)$ & $2(12.5)$ & 1.00 \\
\hline Infundibular Type II & $29(59.2)$ & $17(51.5)$ & $12(75.0)$ & 0.12 \\
\hline Infundibular Type III & $3(6.1)$ & $3(9.1)$ & $0(0)$ & 0.54 \\
\hline \multicolumn{5}{|l|}{ Tumor consistency } \\
\hline Cystic & $12(22.6)$ & $9(26.5)$ & $3(15.8)$ & 0.50 \\
\hline Solid & $13(24.5)$ & $8(23.5)$ & $5(26.3)$ & 0.50 \\
\hline Mixed & $27(50.9)$ & $16(47.1)$ & $11(57.9)$ & 0.57 \\
\hline Preop tumor vol in $\mathrm{cm}^{3}$ (SD) & $9.3(10.9)$ & $9.5(11.6)$ & $9.0(9.8)$ & 0.84 \\
\hline First-time ops & & $10.8(12.5)$ & $7.8(6.5)$ & 0.12 \\
\hline Redo ops & & $4.3(3.5)$ & $10.6(13.4)$ & 0.06 \\
\hline
\end{tabular}

* Except for tumor volume, values are expressed as the number of cases (\%).

ence in PFS curves for the craniotomy and EETS cohorts based on the log-rank test $(p=0.99)$.

The rate of further treatment for recurrent or progressive disease, whether surgical or radiation, was similar in the 2 groups $(23.5 \%$ vs $21.1 \%, p=1.00)$ (Table 7). Surgical retreatment included both craniotomy and EETS. Additionally, the percentage of cases that received further treatment for recurrent or progressive disease following GTR during the index procedure was $8.8 \%$ and $0 \%(\mathrm{p}=$ 0.55 ) for the craniotomy and EETS groups, respectively.

The overall rate of craniotomy in this cohort was $64.2 \%$ and for EETS it was $35.8 \%$. Analysis of the surgical approach preferences of 3 independent surgeons who were not involved in the treatment of this cohort (Table 8) found that one of the surgeons had a strong preference toward craniotomy (85\%), another had a strong EETS preference $(87 \%)$, and the other had a similar preference toward craniotomy (53\%) or EETS (47\%). In evaluating intersurgeon concordance we found a kappa coefficient of -0.039 ( $p$ $=0.7624$ ). This statistic indicates a genuine disagreement between the surgeons as to the best approach. That is, surgeons agree on a particular surgery less than would be expected by chance alone. Further analysis identified only 9 cases (17\%) in which all 3 blinded reviewers agreed on the same surgical approach (5 EETS, 4 craniotomy), which is less than the $25 \%$ odds that there would be agreement based on pure chance. Similarly, there were only 6 cases

\section{TABLE 4. The mean EOR for cases undergoing craniotomy and} EETS

\begin{tabular}{lclll}
\hline \multirow{2}{*}{ Variable } & \multicolumn{3}{c}{ \% Resection (SD) } & \\
\cline { 2 - 4 } & All Ops & Craniotomy & \multicolumn{1}{c}{ EETS } & p Value \\
\hline All cases & $88.8(26.1)$ & $90.7(23.1)$ & $85.6(30.8)$ & 0.77 \\
\hline Initial ops & $92.0(21.7)$ & $89.4(25.5)$ & $98.3(4.1)$ & 0.43 \\
\hline Reops & $80.4(34.6)$ & $96.7(3.9)$ & $68.2(42.6)$ & 0.36 \\
\hline
\end{tabular}

(11\%) in which all 3 blinded reviewers chose concordantly with the actual surgery performed, whereas there was a $25 \%$ chance that this would occur randomly. Taken as a whole, these data firmly support the notion that a surgeon's expertise was the strongest factor driving surgical choice in this series. No other metric was identified as a factor in determining surgical approach, including tumor size, tumor location, tumor shape or consistency, patient age, history of previous surgery, or clinical symptoms.

An analysis of surgical trends over time suggests an ongoing change in philosophy toward each surgical method

TABLE 5. Perioperative and postoperative complications in patients treated with craniotomy and expanded EETS

\begin{tabular}{lcc}
\hline \multirow{2}{*}{ Complications } & \multicolumn{2}{c}{ No. of Cases (\%) } \\
\cline { 2 - 3 } & Craniotomy & EETS \\
\hline No. of cases & $34(64.2)$ & $19(35.8)$ \\
\hline Panhypopituitarism & $13(38.2)$ & $8(42.1)$ \\
\hline DI & $18(52.9)$ & $6(31.6)$ \\
\hline Cranial nerve injury (nonoptic nerve) & $5(14.7)$ & $0(0)$ \\
\hline Hydrocephalus & $3(8.8)$ & $3(15.8)$ \\
\hline Wound dehiscence & $1(2.9)$ & $0(0)$ \\
\hline Cerebral infarct & $1(2.9)$ & $0(0)$ \\
\hline Death & $1(2.9)$ & $1(5.3)$ \\
\hline Subdural hygroma & $1(2.9)$ & $1(5.3)$ \\
\hline Pulmonary embolism & $1(2.9)$ & $0(0)$ \\
\hline Epidural/subdural hematoma & $1(2.9)$ & $0(0)$ \\
\hline Visual deficits & $3(8.8)$ & $0(0)$ \\
\hline Intraventricular hemorrhage & $0(0)$ & $1(5.3)$ \\
\hline CSF leak & $0(0)$ & $5(26.3)$ \\
\hline Short-term memory loss & $0(0)$ & $1(5.3)$ \\
\hline Meningitis & $0(0)$ & $1(5.3)$ \\
\hline
\end{tabular}


TABLE 6. Complications in patients treated with open craniotomy and expanded EETS

\begin{tabular}{lcccc}
\hline \multirow{2}{*}{ Complications } & \multicolumn{3}{c}{ No. of Cases (\%) } & \\
\cline { 2 - 4 } & All Surgeries & Craniotomy & EETS & p Value \\
\hline No. of cases & 53 & $34(64.2)$ & $19(35.8)$ \\
\hline Any & $37(69.8)$ & $27(79.4)$ & $10(52.6)$ & 0.06 \\
\hline Endocrine & $27(50.9)$ & $18(52.9)$ & $9(47.4)$ & 0.78 \\
\hline Cranial nerve injury & $8(15.1)$ & $8(23.5)$ & $0(0)$ & 0.04 \\
\hline $\begin{array}{l}\text { Hydrocephalus/ } \\
\quad \text { hygromas }\end{array}$ & $7(13.2)$ & $4(11.8)$ & $3(15.8)$ & 0.69 \\
\hline Stroke/hemorrhage & $3(5.7)$ & $2(5.9)$ & $1(5.3)$ & 1.00 \\
\hline CSF leak & $5(9.4)$ & $0(0)$ & $5(26.3)$ & 0.004 \\
\hline Death & $2(3.8)$ & $1(2.9)$ & $1(5.3)$ & 1.00 \\
\hline Other & $4(7.5)$ & $2(5.9)$ & $2(10.5)$ & 0.61 \\
\hline
\end{tabular}

in our institution (Fig. 2). The EETS approach was first used in 2005, with the arrival of a surgeon trained in those techniques. Despite the fact that the overall number of cases being resected remained stable, use of EETS increased while the number of craniotomies decreased.

\section{Discussion}

Tumors occupying the midline suprasellar space represent a diverse array of pathological types. Of these, craniopharyngiomas are the most common, accounting for $1 \%-4 \%$ of all intracranial tumors. ${ }^{43}$ Resection and radiation have been the mainstays of treatment. ${ }^{23,27,52}$ Total resection of craniopharyngiomas has been associated with improved long-term outcomes according to several studies, $5,9,12,13,19,41,48,49,53$ however, long-term outcomes in patients with GTR are similar to those receiving partial resection with adjuvant radiation, ${ }^{52}$ leading many surgeons to advocate for less aggressive resections to reduce surgical morbidities.

The constraints imposed by the nearby critical neurovascular structures in the suprasellar region have led to the development of several approaches. Pterional, orbitozygomatic, and subfrontal approaches rely on the surgeon

TABLE 7. Follow-up time, PFS, and recurrence/progression rates for patients treated with craniotomy and expanded EETS*

\begin{tabular}{lccc}
\hline \multicolumn{1}{c}{ Variable } & $\begin{array}{c}\text { Open } \\
\text { Craniotomy }\end{array}$ & EETS & $\begin{array}{c}p \\
\text { Value }\end{array}$ \\
\hline No. of cases & $34(64.2)$ & $19(35.8)$ & \\
\hline Mean follow-up time in days & 1049 & 1022 & 0.80 \\
\hline Mean PFS in days & 760 & 780 & 0.78 \\
\hline First-time ops & 837 & 807 & 0.91 \\
\hline Redo ops & 398 & 742 & 0.27 \\
\hline Cases requiring further treatment & $8(23.5)$ & $4(21.1)$ & 1.00 \\
\hline Op & $6(17.6)$ & $2(10.5)$ & 0.70 \\
\hline Radiation & $2(5.9)$ & $2(10.5)$ & 0.61 \\
\hline Recurrences requiring treatment & $3(8.8)$ & $0(0)$ & 0.55 \\
following GTR & & & \\
\hline
\end{tabular}

${ }^{*}$ Unless otherwise specified, values are expressed as the number of cases (\%).

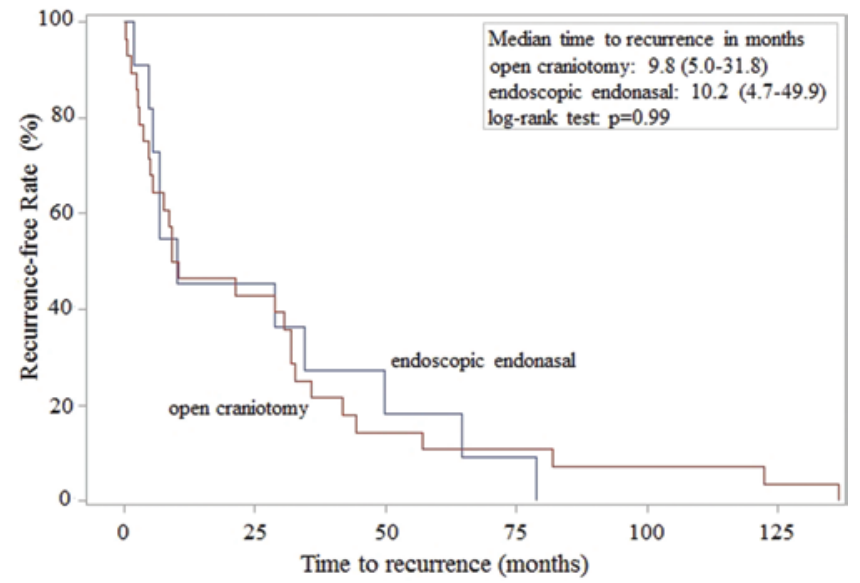

FIG. 1. Kaplan-Meier curves comparing PFS for patients undergoing EETS versus craniotomy for midline suprasellar tumors. Figure is available in color online only.

developing "corridors" to access the suprasellar space, requiring retraction of brain tissue, and working between neurovascular structures. ${ }^{29,32,35,38,52,53}$ This may result in highly morbid perioperative complications, such as cerebral edema, venous infarct, carotid artery injury, stroke, and cranial nerve injury.

First reported by Locatelli et al., endoscopic approaches to the skull base have become an increasingly popular method of treatment of suprasellar lesions. ${ }^{2,4,7,16,18,36}$ EETS has several advantages over traditional open approaches, including direct access to the skull base without retraction of neural tissue or manipulation of neurovascular structures. ${ }^{3,15,16,24,27,31}$ Additionally, the third ventricle and hypothalamus can be well visualized using endoscopic endonasal approaches. ${ }^{15}$

Extended microscopic transsphenoidal approaches have been described for treatment of suprasellar lesions. ${ }^{22,29,40}$ EETS has allowed significantly wider surgical exposure than the traditional microscopic approach. Transplanum and transclival extensions of the expanded endoscopic endonasal approach permit access to the suprasellar and prepontine spaces, respectively, thus providing a significantly larger working window for resection. ${ }^{44}$ In addition, EETS can allow access to tumors located in the retroinfundibular space via transposition of the pituitary gland..$^{17,26}$

Despite these advantages, several limitations do exist to endoscopic endonasal approaches. Tumors extending lateral and/or encasing structures such as the supraclinoid carotid artery may be difficult to resect via EETS, and may be more amenable to a transcranial approach. ${ }^{8,10}$ Moreover, a steep learning curve exists for the performance of these approaches, and often requires a neurosurgeon and otolaryngologist trained in skull base approaches. ${ }^{39}$

At our institution, although the total number of surgeries for midline suprasellar tumors has remained fairly constant, there has been a steady increase in the use of EETS since 2007, with a concomitant decrease in craniotomies. A similar trend has been noted in many other centers as well. We suspect that this trend will continue and that it reflects a growing consensus that EETS has several advantages over craniotomy for these growths. 
TABLE 8. Comparison of blinded analysis of cases in the series with actual surgeon choice

\begin{tabular}{|c|c|c|c|c|}
\hline $\begin{array}{l}\text { Case } \\
\text { No. }\end{array}$ & $\begin{array}{l}\text { Blinded } \\
\text { Surgeon } 1\end{array}$ & $\begin{array}{l}\text { Blinded } \\
\text { Surgeon } 2\end{array}$ & $\begin{array}{c}\text { Blinded } \\
\text { Surgeon } 3\end{array}$ & $\begin{array}{c}\text { Actual Surgeon } \\
\text { Choice }\end{array}$ \\
\hline 1 & Craniotomy & Craniotomy & EETS & EETS \\
\hline 2 & Craniotomy & EETS & EETS & EETS \\
\hline 3 & Craniotomy & Craniotomy & EETS & EETS \\
\hline 4 & EETS & EETS & EETS & EETS \\
\hline 5 & Craniotomy & EETS & EETS & EETS \\
\hline 6 & Craniotomy & Craniotomy & EETS & EETS \\
\hline 7 & Craniotomy & EETS & EETS & EETS \\
\hline 8 & Craniotomy & Craniotomy & EETS & EETS \\
\hline 9 & Craniotomy & Craniotomy & EETS & EETS \\
\hline 10 & Craniotomy & Craniotomy & EETS & EETS \\
\hline 11 & Craniotomy & EETS & EETS & EETS \\
\hline 12 & Craniotomy & Craniotomy & EETS & EETS \\
\hline 13 & EETS & EETS & EETS & EETS \\
\hline 14 & Craniotomy & EETS & EETS & EETS \\
\hline 15 & Craniotomy & Craniotomy & EETS & EETS \\
\hline 16 & Craniotomy & Craniotomy & EETS & EETS \\
\hline 17 & Craniotomy & Craniotomy & EETS & EETS \\
\hline 18 & Craniotomy & EETS & EETS & EETS \\
\hline 19 & Craniotomy & EETS & EETS & EETS \\
\hline 20 & Craniotomy & EETS & EETS & Craniotomy \\
\hline 21 & Craniotomy & Craniotomy & Craniotomy & Craniotomy \\
\hline 22 & EETS & EETS & EETS & Craniotomy \\
\hline 23 & Craniotomy & EETS & EETS & Craniotomy \\
\hline 24 & Craniotomy & Craniotomy & EETS & Craniotomy \\
\hline 25 & EETS & EETS & EETS & Craniotomy \\
\hline 26 & Craniotomy & Craniotomy & EETS & Craniotomy \\
\hline 27 & Craniotomy & Craniotomy & EETS & Craniotomy \\
\hline 28 & Craniotomy & EETS & EETS & Craniotomy \\
\hline 29 & Craniotomy & Craniotomy & EETS & Craniotomy \\
\hline 30 & Craniotomy & Craniotomy & EETS & Craniotomy \\
\hline 31 & Craniotomy & EETS & EETS & Craniotomy \\
\hline 32 & EETS & Craniotomy & EETS & Craniotomy \\
\hline 33 & Craniotomy & Craniotomy & EETS & Craniotomy \\
\hline 34 & Craniotomy & EETS & EETS & Craniotomy \\
\hline 35 & Craniotomy & Craniotomy & Craniotomy & Craniotomy \\
\hline 36 & Craniotomy & Craniotomy & Craniotomy & Craniotomy \\
\hline 37 & Craniotomy & Craniotomy & EETS & Craniotomy \\
\hline 38 & Craniotomy & Craniotomy & EETS & Craniotomy \\
\hline 39 & Craniotomy & Craniotomy & EETS & Craniotomy \\
\hline 40 & Craniotomy & EETS & EETS & Craniotomy \\
\hline 41 & Craniotomy & Craniotomy & EETS & Craniotomy \\
\hline 42 & Craniotomy & EETS & EETS & Craniotomy \\
\hline 43 & Craniotomy & Craniotomy & EETS & Craniotomy \\
\hline 44 & Craniotomy & EETS & EETS & Craniotomy \\
\hline 45 & Craniotomy & Craniotomy & Craniotomy & Craniotomy \\
\hline 46 & Craniotomy & EETS & EETS & Craniotomy \\
\hline 47 & Craniotomy & EETS & EETS & Craniotomy \\
\hline
\end{tabular}

TABLE 8. Comparison of blinded analysis of cases in the series with actual surgeon choice (continued)

\begin{tabular}{cllll}
\hline $\begin{array}{c}\text { Case } \\
\text { No. }\end{array}$ & $\begin{array}{c}\text { Blinded } \\
\text { Surgeon 1 }\end{array}$ & $\begin{array}{c}\text { Blinded } \\
\text { Surgeon 2 }\end{array}$ & $\begin{array}{c}\text { Blinded } \\
\text { Surgeon 3 }\end{array}$ & $\begin{array}{c}\text { Actual Surgeon } \\
\text { Choice }\end{array}$ \\
\hline 48 & EETS & EETS & EETS & Craniotomy \\
\hline 49 & Craniotomy & EETS & EETS & Craniotomy \\
\hline 50 & Craniotomy & Craniotomy & EETS & Craniotomy \\
\hline 51 & EETS & Craniotomy & Craniotomy & Craniotomy \\
\hline 52 & Craniotomy & EETS & Craniotomy & EETS \\
\hline 53 & EETS & EETS & Craniotomy & Craniotomy \\
\hline
\end{tabular}

\section{Baseline Characteristics of Patients}

No significant differences were found in the demographic profile between the EETS and craniotomy groups. Similarly, no significant differences were found in the presenting symptoms between the 2 cohorts. Moreover, the relative frequencies of different tumor types were similar between the 2 groups, as were the tumor consistencies and preoperative volume. Among craniopharyngiomas, the distribution of tumor location relative to the infundibulum was similar between the 2 cohorts, as were the histological subtypes (adamantinomatous vs papillary). These findings suggest that the outcomes reported are not reflective of a selection bias toward one procedure or another based on anatomical issues or symptoms, and that the data reflect a reliable comparison between surgical methods.

\section{Extent of Resection}

A large systematic review of the literature by Komotar et al. compared data from 88 studies reporting EETS, microscopic transsphenoidal surgery, or craniotomy for resection of craniopharyngiomas, totaling 3470 patients..$^{28}$ That study concluded that significantly greater rates of GTR occurred in the EETS cohort compared with the cranial cohort, whereas higher rates of partial resection were found in the cranial group. Of note, none of the papers that were used to create this systematic review directly compared EETS and craniotomy at a single institution, but rather reported results for either only cranial resections or only EETS resections, making direct comparisons more difficult than in our series.

It is difficult to directly compare the EOR in our study, in which it was measured as a continuous variable, to the EOR in this earlier review, in which it was categorized into discrete variables. Nonetheless, it is interesting to observe that Komotar et al. did report a difference in the EOR between cohorts, whereas we did not observe this difference. One possible explanation could be the difference in preoperative tumor characteristics between the 2 groups in their review. For example, the average cross-sectional lesion size was smaller in the EETS group than in the craniotomy group ( $2.9 \mathrm{~cm}$ vs $3.9 \mathrm{~cm}$, respectively). Moreover, Komotar et al. summarized results from many different institutions. Each institution probably had its own biases regarding the goals of resection. Although some institutions may have favored less aggressive resection followed by radiation, others may have favored attempting a total resection when feasible. This bias introduces a substan- 


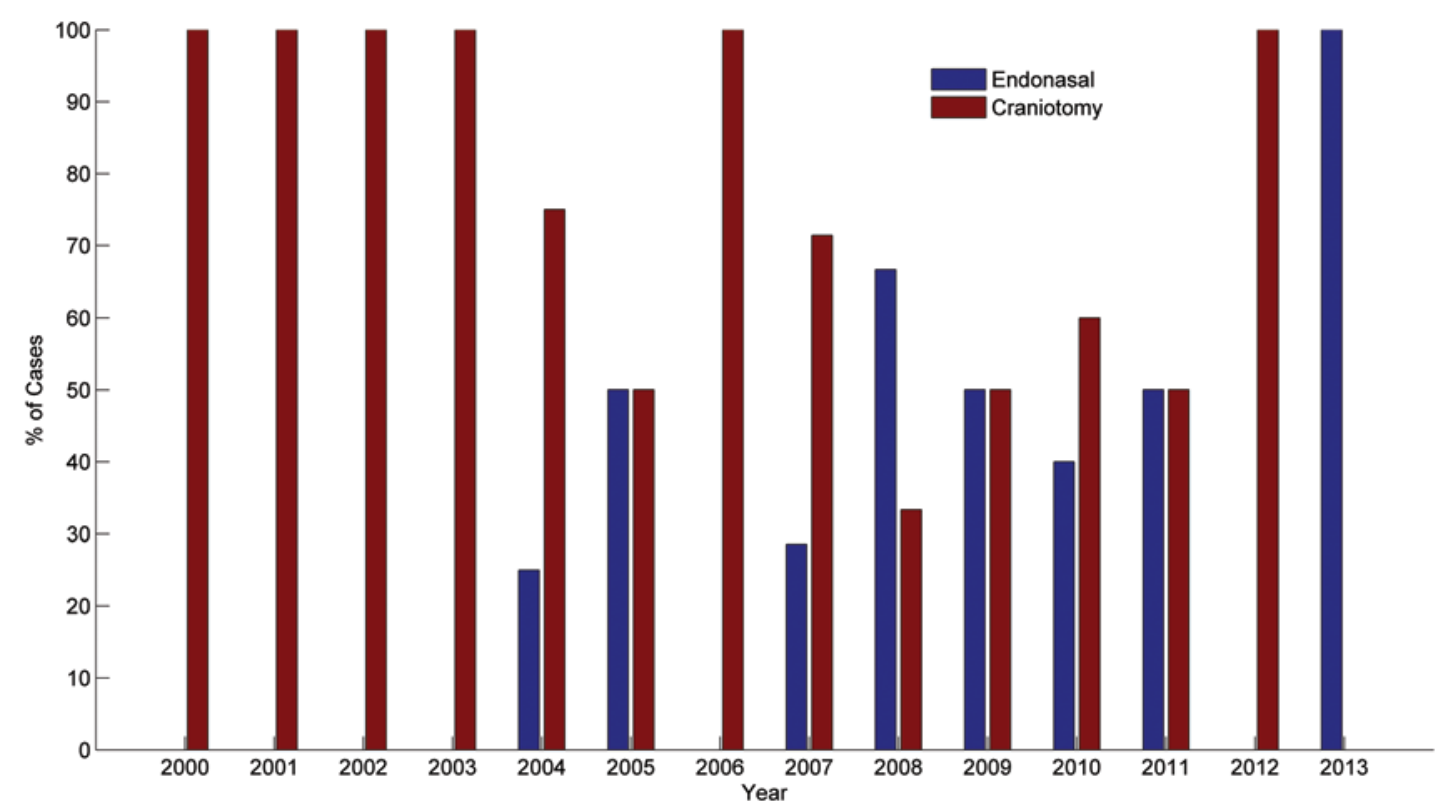

FIG. 2. Bar graph showing percentage of cases treated with EETS versus craniotomy between 2000 and 2013 . Figure is available in color online only.

tial confounding factor that may influence the difference in EOR seen, which would be less of an issue in singleinstitution studies with a consistent strategy.

Other single-center reports provide further support to our findings. Frank et al. reported a series of 10 patients with craniopharyngiomas who underwent resection via an EETS; GTR was achieved in 7 of 10 patients..$^{16}$ Koutourousiou et al. reported a GTR rate of $31.9 \%$ and a > $95 \%$ resection rate of $61.7 \%$ in their cohort of adult patients who underwent EETS for craniopharyngioma. ${ }^{30}$ Leng et al. reported a GTR rate of $86 \%$ among patients with craniopharyngioma who underwent EETS for which total resection was the intended goal. ${ }^{33}$ Gardner et al. reported a mean EOR of $89.6 \%$ for initial surgery, and a mean EOR of $75.2 \%$ for recurrent lesions in their cohort treated via EETS. ${ }^{17}$ These rates are consistent with our findings. These rates are also comparable to reported rates in the literature for suprasellar tumors resected via cranial routes. ${ }^{1,9,14,41,42,45,47,49,50,53}$

\section{Endocrine Complications}

In our study, no significant difference in the rate of endocrine complications was found between the 2 groups. Frank et al. reported permanent DI in 3 of 10 patients, consistent with our findings. ${ }^{16}$ Other EETS series have reported rates of $32.3 \%$ and $42 \% .^{30,34}$ Komotar et al. reported DI in $27.7 \%$ of patients in the EETS group, whereas they found a DI rate of $54.8 \%$ in the cranial group. ${ }^{28}$ This is also comparable to our findings, in which the rate of DI was $31.6 \%$ and $52.9 \%$ in the EETS and craniotomy group, respectively. Interestingly, Komotar et al. found this difference to reach statistical significance, ${ }^{28}$ whereas we found no statistical difference. The current study may be underpowered to detect such a difference in postoperative rates of DI.

Moreover, Komotar et al. reported panhypopituitarism in $48.1 \%$ in the craniotomy group, and a rate of $47.1 \%$ in the EETS group. ${ }^{28}$ This is also comparable to our findings, in which we found a panhypopituitarism rate of $38.2 \%$ and $42.1 \%$ in the craniotomy and EETS groups, respectively. Koutourousiou et al. reported a similar rate of $37.5 \%$ for pituitary dysfunction after EETS surgery, ${ }^{30}$ and Leng et al. reported a $38 \%$ rate. ${ }^{34}$ Several studies have also previously reported postoperative rates of panhypopituitarism and DI to be within the same range following craniotomy. ${ }^{1,14,34,42,45,49,50,53}$ This is consistent with our observation that there was no significant difference in endocrine complication rates between the EETS and craniotomy cohorts.

On the other hand, Gardner et al. reported a postoperative DI rate of $8 \%$ and a panhypopituitarism rate of $18 \%$ in a series of 16 patients who underwent EETS for suprasellar craniopharyngiomas. ${ }^{18}$ One possible explanation for this discrepancy could be that in our EETS cohort 75\% of the cases were Type II tumors, whereas in the Gardner series Type II tumors represented approximately $31 \%$ of the cases. This may have resulted in a greater rate of injury or sacrifice of the pituitary stalk during resection in the current study.

\section{Postoperative CSF Leaks}

As expected, the incidence of postoperative CSF leaks was significantly greater in the EETS group, occurring in $26.3 \%$ of our cases. The CSF leak rate in the Komotar review was also significantly higher in the EETS group (18.4\%) compared with the craniotomy group (2.6\%). ${ }^{28}$ Frank et al. reported a postoperative CSF leak in 3 of 10 patients (30\%) undergoing EETS. ${ }^{16}$ Koutourousiou et al. reported a CSF leak rate of $27.7 \%$ in their cohort of patients. ${ }^{30}$ These are comparable to the CSF leak rates found in the EETS cohort in this study. Several other series involving endoscopic endonasal approaches have reported a CSF leak rate in this range as well., 17,46

More recent series in which pedicled nasoseptal flap 
was used have reported CSF leak rates less than $10 \%$, and even between $0 \%$ and $4 \%$ in some more recent series. ${ }^{20,33,34,51}$ Koutourousiou et al. found a CSF leak rate of $58.8 \%$ among patients who did not undergo a flap reconstruction, whereas they found a CSF leak rate of $10.6 \%$ among patients who did have a vascularized flap reconstruction..$^{30}$ As of 2011, we have routinely used a nasoseptal flap in all EETS cases, with a reduced rate of CSF leak of $14 \%$, and with no leaks in our last 7 patients. Given the small sample size in this study, it is difficult to ascertain whether the CSF leak rate improved due to the use of nasoseptal flaps, or simply due to the improved surgical technique.

\section{Optic Nerve Injury}

We noted an $8.8 \%$ incidence of postoperative visual deficit in the craniotomy group and none $(0 \%)$ in the EETS group. Similarly, Frank et al. reported no visual worsening after surgery in their series of 10 patients, ${ }^{16}$ and Gardner et al. reported no worsening of vision in their series of 16 patients who underwent EETS. ${ }^{17}$ Koutourousiou et al. reported that 1 patient in their cohort of 47 patients $(2 \%)$ experienced a new visual deficit after EETS surgery, ${ }^{30}$ and Leng et al. reported that 2 patients experienced worsening vision postoperatively in their series of 26 cases ${ }^{34}$ Overall the rate of new visual deficit was 3/99 (3\%).

In contrast, several studies report a fairly substantial rate of postoperative visual deficits when using cranial approaches. Fahlbusch et al. noted a rate of postoperative visual deterioration of $14.3 \%$ in the transcranial cohort and $0 \%$ in the transsphenoidal cohort. ${ }^{14}$ Similarly, Chakrabarti et al. found a $17 \%$ incidence of postoperative visual deficit in the craniotomy cohort versus $3 \%$ in the transsphenoidal cohort. ${ }^{5}$ Whereas the cranial results are directly relevant to the current series, the transsphenoidal data are harder to correlate because both series used the transsphenoidal route for cystic tumors of the sella, and neither used the EETS approach described in this series. These multiple series support the view that cranial surgery is associated with a higher risk of postoperative visual deterioration than is EETS surgery.

\section{Cranial Nerve Injury Other Than Optic}

We found a significantly greater incidence of postoperative cranial nerve injury in the craniotomy group $(14.7 \%)$ versus that in the EETS group $(0 \%)$. This included injuries to the oculomotor, trochlear, olfactory, and frontalis branch of the facial nerves. Frank et al. reported $1(10 \%)$ third nerve palsy in their series of 10 patients undergoing EETS for resection of craniopharyngioma. ${ }^{16}$ Moreover, Koutourousiou et al. reported the postoperative incidence of cranial nerve palsy to be $4.2 \%$ in their adult cohort. ${ }^{30}$ When combining both optic and nonoptic cranial nerve injuries, we found a significantly higher rate of cranial nerve injury in the craniotomy group compared with the EETS group. This probably reflects the fact that a greater degree of manipulation of neural structures is required in the cranial approaches.

\section{Other Complications}

The incidence of hydrocephalus in the EETS cohort in this study was found to be $15.8 \%$. Koutourousiou et al. reported a rate of $12.7 \%$ in their series of patients treated with EETS. ${ }^{30}$ Other studies have also reported similar rates of postoperative hydrocephalus after EETS surgery. 2,14,21,37

Other complication rates from the review by Komotar et al. closely matched the complication rates found in this study. ${ }^{28}$ The rates of wound infections/dehiscence, meningitis, strokes, hemorrhage, and death for both groups were very similar to those found in this study. Moreover, no significant differences were found for these complications between the 2 groups, similar to the findings of this study. We did not report postoperative weight gain in our results. Postoperative obesity is a well-documented sequela of craniopharyngioma resection, ${ }^{34}$ probably due to hypothalamic injury. Information regarding weight status was not reliably available for each patient, and thus we were not able to assess the incidence of this issue. Other authors have reported difficulty in assessing obesity postoperatively in adult patients, because it is not clear whether the weight gain is from hypothalamic injury, exogenous steroid use, or a change in diet and exercise patterns. ${ }^{30,34}$

\section{Rates of PFS and Recurrence}

The PFS was quite similar between the 2 groups in our study, as was the proportion of cases that went on to require further treatment for recurrent or progressive disease. Interestingly, the PFS of patients who underwent a repeat operation was shorter in the craniotomy group compared with the EETS group; however this did not reach statistical significance. The mean follow-up time for the reoperation cases in the EETS group (1318 days) was longer than that for the reoperation cases in the craniotomy group (979 days). The longer mean follow-up period in the recurrent EETS group would lend itself to a longer mean PFS. Although not a perfect statistic, the mean PFS/mean follow-up ratio was similar in both groups $(0.56$ for the recurrent EETS group vs 0.41 for the recurrent craniotomy group). There was no significant difference in the mean follow-up between the 2 groups when including all cases, both first-time operations and reoperations. Therefore, a comparison of PFS using the entire cohort is more meaningful.

The review by Komotar et al. found a mean time to recurrence of disease of approximately 906 days in the craniotomy group versus 402 days for the EETS group. ${ }^{28}$ However, a statistical significance was not reported for this difference. This is somewhat confusing because they found an increased rate of GTR in the EETS group, and similar rates of adjuvant radiation/radiosurgery in both groups. This difference may be at least partly attributed to the difference in mean follow-up time between the 2 groups: 65.2 months (1956 days) for the craniotomy group and 28.9 months (867 days) for the EETS group, as well as a larger number of cases in the craniotomy group. Although we did not find any significant difference in the PFS in our study, it is difficult to compare our results to the Komotar review given the differences in mean follow-up times between the studies.

Additionally, Komotar et al. found a tumor recurrence rate of $28.2 \%$ and $18.4 \%$ in the craniotomy and EETS groups, respectively, but the difference was not statistical- 
ly significant. ${ }^{28}$ These results are similar to our findings. Koutourousiou et al. reported a recurrence rate of $31.9 \%$ in their cohort of 47 adult patients with craniopharyngiomas treated with EETS surgery over a mean follow-up time of 39 months, and a mean recurrence-free period of 15.1 months. ${ }^{30}$

We noted no recurrences after a GTR via EETS, but a $21 \%$ rate of recurrence overall among all patients receiving EETS surgery, reflecting the significance of EOR regarding recurrence. Gardner et al. reported no recurrences in patients who underwent GTR in their series of 16 patients treated with EETS. ${ }^{17}$ Similarly, Leng et al. also found no recurrences in their subset of patients who underwent GTR via an EETS approach. ${ }^{34}$ Koutourousiou et al. found no significant difference in the rate of recurrence between cases in which they achieved GTR versus subtotal resection via an EETS approach..$^{30}$ One possible explanation for this could be that the proportion of the subtotal resection cases in which they achieved near-complete $(>95 \%)$ resection may have been high, thereby yielding similar results to those undergoing GTR.

\section{Potential Limitations}

A potential confounding factor in a retrospective study of this nature is selection bias. Are our data limited by such a bias? For example, early in our series almost all cases were treated via craniotomy, but toward the end most were treated via EETS. Did this reflect a temporal selection bias? Analysis indicates that this perceived temporal bias was driven by a surgeon's preference and expertise. That is, the surgical preference depicted in our series is strongly aligned with the expertise available in our surgeons. The high preponderance of EETS surgeries in the latter phase of our series is driven by the arrival of a surgeon who has significant expertise with the EETS approach. In the absence of his presence at our institution, surgeons preferred the craniotomy approach.

However, selection bias may also be masked by other variables. For example, tumor volume and clinical presentation may not reflect issues such as tumor location relative to neurovascular structures, tumor consistency and degree of calcification, previous surgical approaches, or other such factors. These factors may strongly influence a surgical choice and lead to better or worse observed outcomes. We attempted to address these issues by asking 3 neurosurgeons with extensive clinical experience in managing suprasellar tumors to evaluate the images and clinical data for each patient in blinded fashion, and to select a surgical approach. If there was a strong tendency to select one surgical approach due to these sorts of characteristics, this would be revealed by concordance analysis of these choices. Our analysis, however, indicated no case-specific concordances, but rather that individual surgeon preference was the only factor that influenced surgical choice. Complete concordance of surgical approach among the 3 blinded reviewers would be expected in $25 \%$ of cases by pure chance, yet the concordance rate in our analysis was only $17 \%$ ( 9 cases). Furthermore, of those 9 cases there were only $6(11 \%)$ in which the blinded reviewers all agreed with the surgical approach actually chosen (2 EETS, 4 craniotomy), and there were $12.5 \%$ odds that this would occur by chance variation only. This analysis firmly suggests that selection bias does not explain our findings and supports our conclusions regarding the benefits and disadvantages of each method.

In the classic sense, all surgical series are subject to some degree of selection bias because each surgeon chooses an approach that he or she believes will best accomplish the surgical goal. Such lack of control is present in many neurosurgical studies. This form of selection bias takes into account individual training and experience, along with issues about the individual tumor, yet does not necessarily detract from the validity of observation. ${ }^{6}$ The nature of this form of selection bias is becoming more recognized in surgical studies, and in fact it has been suggested that this bias is built into the design of RCTs.

It is worth noting that in a conventional RCT the patients are typically randomized according the intervention, regardless of a surgeon's level of expertise. However, a surgeon's experience and training influences the efficacy and eventual clinical outcomes associated with a particular surgical approach. A more relevant approach would be one that randomizes patients to a surgical approach based on a surgeon's expertise level (expertise-based RCT). Expertise-based randomization instead allocates patients to surgeons with expertise in the specific interventions under investigation who are committed to performing a specific surgical procedure (e.g., craniotomy or EETS) based on their expertise. So, expertise-based trials may well be superior to conventional RCTs when comparing competing techniques, because they help overcome some of the limitations involved with RCTs: differential expertise bias, ethical concerns about conventional RCTs, and improved trial feasibility, to name a few. ${ }^{11}$

Certainly a prospective expertise-based RCT evaluating outcomes between surgeons who favor craniotomy and those who favor EETS is the most definitive way to address this issue, but in the absence of such a study our data suggest that selection bias cannot explain our results, and support the observation made.

A second limitation of this study is that the sample sizes in our cohort were relatively small. Our sample size was comparable to several other studies that have examined the use of EETS, and therefore carries the same limitations as those retrospective studies. This small sample size may have resulted in an insufficient power in our study to detect a difference in several variables.

A third limitation is that although the vast majority of the cases were craniopharyngiomas, there were a few pituicytomas and only 1 xanthogranuloma. This may have influenced our outcomes to some degree, including recurrence rates and PFS. Most of the other studies examining the use of endoscopic endonasal techniques were solely for the resection of craniopharyngiomas. Therefore, there may not be a fair comparison of outcomes between our study and these studies in the literature. It should be noted, however, that pituicytoma and xanthogranuloma cases represented only a very small proportion of the cases in our cohort. From the standpoint of the surgical approach, expected complications of surgery, and overall survival, the results should be consistent with those seen for Type II infundibular craniopharyngiomas. Since the EOR and 
complications were the primary outcomes analyzed in this series, we think their inclusion is justified, but it may make it harder to draw broad conclusions about PFS for craniopharyngiomas.

Finally, although our mean follow-up time was comparable to that reported for several other studies, the amount of time may be insufficient to assess the true rate of recurrence and PFS. Longer-term studies are needed to better resolve this issue.

\section{Conclusions}

Both EETS and craniotomy can successfully remove craniopharyngiomas and similar midline suprasellar masses. The EOR, recurrence rate, and PFS appear to be similar when either EETS or craniotomy was used at our center over a 13-year period. Whereas the rate of CSF leakage was found to be significantly higher in the EETS cohort, the rate of cranial nerve injury and other neurovascular complications was found to be significantly higher in the craniotomy cohort. In light of the long-term consequences of neurological injury and the relative ease with which CSF leaks can be repaired, we believe that our data support the conclusion that EETS surgery is the preferred approach for removal of suprasellar craniopharyngiomas and similar lesions whenever feasible, and we advocate for increased use of the EETS approach.

\section{Acknowledgment}

We thank Serguei Bannykh, MD, PhD, Department of Pathology, Cedars-Sinai Medical Center.

\section{References}

1. Baskin DS, Wilson CB: Surgical management of craniopharyngiomas. A review of 74 cases. J Neurosurg 65:22-27, 1986

2. Campbell PG, McGettigan B, Luginbuhl A, Yadla S, Rosen M, Evans JJ: Endocrinological and ophthalmological consequences of an initial endonasal endoscopic approach for resection of craniopharyngiomas. Neurosurg Focus 28(4):E8, 2010

3. Cappabianca P, Cavallo LM, Colao A, Del Basso De Caro M, Esposito F, Cirillo S, et al: Endoscopic endonasal transsphenoidal approach: outcome analysis of 100 consecutive procedures. Minim Invasive Neurosurg 45:193-200, 2002

4. Cavallo LM, Prevedello DM, Solari D, Gardner PA, Esposito F, Snyderman CH, et al: Extended endoscopic endonasal transsphenoidal approach for residual or recurrent craniopharyngiomas. J Neurosurg 111:578-589, 2009

5. Chakrabarti I, Amar AP, Couldwell W, Weiss MH: Longterm neurological, visual, and endocrine outcomes following transnasal resection of craniopharyngioma. J Neurosurg 102:650-657, 2005

6. Dallapiazza R, Bond AE, Grober Y, Louis RG, Payne SC, Oldfield EH, et al: Retrospective analysis of a concurrent series of microscopic versus endoscopic transsphenoidal surgeries for Knosp Grades 0-2 nonfunctioning pituitary macroadenomas at a single institution. J Neurosurg 121:511-517, 2014

7. de Divitiis E, Cappabianca P, Cavallo LM, Esposito F, de Divitiis O, Messina A: Extended endoscopic transsphenoidal approach for extrasellar craniopharyngiomas. Neurosurgery 61 (5 Suppl 2):219-228, 2007

8. de Divitiis E, Cavallo LM, Cappabianca P, Esposito F: Ex- tended endoscopic endonasal transsphenoidal approach for the removal of suprasellar tumors: Part 2 . Neurosurgery 60:46-59, 2007

9. De Vile CJ, Grant DB, Kendall BE, Neville BG, Stanhope R, Watkins KE, et al: Management of childhood craniopharyngioma: can the morbidity of radical surgery be predicted? J Neurosurg 85:73-81, 1996

10. Dehdashti AR, Ganna A, Witterick I, Gentili F: Expanded endoscopic endonasal approach for anterior cranial base and suprasellar lesions: indications and limitations. Neurosurgery 64:677-689, 2009

11. Devereaux PJ, Bhandari M, Clarke M, Montori VM, Cook DJ, Yusuf S, et al: Need for expertise based randomised controlled trials. BMJ 330:88, 2005

12. Dhellemmes P, Vinchon M: Radical resection for craniopharyngiomas in children: surgical technique and clinical results. J Pediatr Endocrinol Metab 19 (Suppl 1):329-335, 2006

13. Duff J, Meyer FB, Ilstrup DM, Laws ER Jr, Schleck CD, Scheithauer BW: Long-term outcomes for surgically resected craniopharyngiomas. Neurosurgery 46:291-305, 2000

14. Fahlbusch R, Honegger J, Paulus W, Huk W, Buchfelder M: Surgical treatment of craniopharyngiomas: experience with 168 patients. J Neurosurg 90:237-250, 1999

15. Fernandez-Miranda JC, Gardner PA, Snyderman CH, Devaney KO, Strojan P, Suárez C, et al: Craniopharyngioma: a pathologic, clinical, and surgical review. Head Neck 34:1036-1044, 2012

16. Frank G, Pasquini E, Doglietto F, Mazzatenta D, Sciarretta V, Farneti G, et al: The endoscopic extended transsphenoidal approach for craniopharyngiomas. Neurosurgery 59:ONS75ONS83, 2006

17. Gardner PA, Kassam AB, Snyderman CH, Carrau RL, Mintz $\mathrm{AH}$, Grahovac S, et al: Outcomes following endoscopic, expanded endonasal resection of suprasellar craniopharyngiomas: a case series. J Neurosurg 109:6-16, 2008

18. Gardner PA, Prevedello DM, Kassam AB, Snyderman CH, Carrau RL, Mintz AH: The evolution of the endonasal approach for craniopharyngiomas. J Neurosurg 108:10431047,2008

19. Isaac MA, Hahn SS, Kim JA, Bogart JA, Chung CT: Management of craniopharyngioma. Cancer J 7:516-520, 2001

20. Jane JA Jr, Kiehna E, Payne SC, Early SV, Laws ER Jr: Early outcomes of endoscopic transsphenoidal surgery for adult craniopharyngiomas. Neurosurg Focus 28(4):E9, 2010

21. Jane JA Jr, Prevedello DM, Alden TD, Laws ER Jr: The transsphenoidal resection of pediatric craniopharyngiomas: a case series. J Neurosurg Pediatr 5:49-60, 2010

22. Kaptain GJ, Vincent DA, Sheehan JP, Laws ER Jr: Transsphenoidal approaches for the extracapsular resection of midline suprasellar and anterior cranial base lesions. Neurosurgery 49:94-101, 2001

23. Karavitaki N, Cudlip S, Adams CB, Wass JA: Craniopharyngiomas. Endocr Rev 27:371-397, 2006

24. Kassam A, Snyderman CH, Mintz A, Gardner P, Carrau RL: Expanded endonasal approach: the rostrocaudal axis. Part I. Crista galli to the sella turcica. Neurosurg Focus 19(1):E3, 2005

25. Kassam AB, Gardner PA, Snyderman CH, Carrau RL, Mintz AH, Prevedello DM: Expanded endonasal approach, a fully endoscopic transnasal approach for the resection of midline suprasellar craniopharyngiomas: a new classification based on the infundibulum. J Neurosurg 108:715-728, 2008

26. Kassam AB, Prevedello DM, Thomas A, Gardner P, Mintz A, Snyderman C, et al: Endoscopic endonasal pituitary transposition for a transdorsum sellae approach to the interpeduncular cistern. Neurosurgery 62 (3 Suppl 1):57-74, 2008

27. Komotar RJ, Roguski M, Bruce JN: Surgical management of craniopharyngiomas. J Neurooncol 92:283-296, 2009 
28. Komotar RJ, Starke RM, Raper DM, Anand VK, Schwartz TH: Endoscopic endonasal compared with microscopic transsphenoidal and open transcranial resection of craniopharyngiomas. World Neurosurg 77:329-341, 2012

29. Kouri JG, Chen MY, Watson JC, Oldfield EH: Resection of suprasellar tumors by using a modified transsphenoidal approach. Report of four cases. J Neurosurg 92:1028-1035, 2000

30. Koutourousiou M, Gardner PA, Fernandez-Miranda JC, Tyler-Kabara EC, Wang EW, Snyderman CH: Endoscopic endonasal surgery for craniopharyngiomas: surgical outcome in 64 patients. J Neurosurg 119:1194-1207, 2013

31. Laufer I, Anand VK, Schwartz TH: Endoscopic, endonasal extended transsphenoidal, transplanum transtuberculum approach for resection of suprasellar lesions. J Neurosurg 106:400-406, 2007

32. Laws ER, Kanter AS, Jane JA Jr, Dumont AS: Extended transsphenoidal approach. J Neurosurg 102:825-828, 2005

33. Leng LZ, Brown S, Anand VK, Schwartz TH: "Gasket-seal" watertight closure in minimal-access endoscopic cranial base surgery. Neurosurgery 62 (5 Suppl 2):ONSE342-ONSE343, 2008

34. Leng LZ, Greenfield JP, Souweidane MM, Anand VK, Schwartz TH: Endoscopic, endonasal resection of craniopharyngiomas: analysis of outcome including extent of resection, cerebrospinal fluid leak, return to preoperative productivity, and body mass index. Neurosurgery 70:110-124, 2012

35. Liu JK, Cole CD, Kestle JR, Brockmeyer DL, Walker ML: Cranial base strategies for resection of craniopharyngioma in children. Neurosurg Focus 18(6A):E9, 2005

36. Locatelli D, Levi D, Rampa F, Pezzotta S, Castelnuovo P: Endoscopic approach for the treatment of relapses in cystic craniopharyngiomas. Childs Nerv Syst 20:863-867, 2004

37. Maira G, Anile C, Albanese A, Cabezas D, Pardi F, Vignati A: The role of transsphenoidal surgery in the treatment of craniopharyngiomas. J Neurosurg 100:445-451, 2004

38. Maira G, Anile C, Rossi GF, Colosimo C: Surgical treatment of craniopharyngiomas: an evaluation of the transsphenoidal and pterional approaches. Neurosurgery 36:715-724, 1995

39. Mamelak AN, Carmichael J, Bonert VH, Cooper O, Melmed $\mathrm{S}$ : Single-surgeon fully endoscopic endonasal transsphenoidal surgery: outcomes in three-hundred consecutive cases. Pituitary 16:393-401, 2013

40. Mason RB, Nieman LK, Doppman JL, Oldfield EH: Selective excision of adenomas originating in or extending into the pituitary stalk with preservation of pituitary function. J Neurosurg 87:343-351, 1997

41. McMurry FG, Hardy RW Jr, Dohn DF, Sadar E, Gardner WJ: Long term results in the management of craniopharyngiomas. Neurosurgery 1:238-241, 1977

42. Minamida Y, Mikami T, Hashi K, Houkin K: Surgical management of the recurrence and regrowth of craniopharyngiomas. J Neurosurg 103:224-232, 2005

43. Samii M, Tatagiba M: Surgical management of craniopharyngiomas: a review. Neurol Med Chir (Tokyo) 37:141-149, 1997

44. Schwartz TH, Fraser JF, Brown S, Tabaee A, Kacker A, Anand VK: Endoscopic cranial base surgery: classification of operative approaches. Neurosurgery 62:991-1005, 2008
45. Shirane R, Ching-Chan S, Kusaka Y, Jokura H, Yoshimoto T: Surgical outcomes in 31 patients with craniopharyngiomas extending outside the suprasellar cistern: an evaluation of the frontobasal interhemispheric approach. J Neurosurg 96:704-712, 2002

46. Stamm AC, Vellutini E, Harvey RJ, Nogeira JF Jr, Herman DR: Endoscopic transnasal craniotomy and the resection of craniopharyngioma. Laryngoscope 118:1142-1148, 2008

47. Symon L, Pell MF, Habib AH: Radical excision of craniopharyngioma by the temporal route: a review of 50 patients. Br J Neurosurg 5:539-549, 1991

48. Tena-Suck ML, Salinas-Lara C, Arce-Arellano RI, RembaoBojórquez D, Morales-Espinosa D, Sotelo J, et al: Clinicopathological and immunohistochemical characteristics associated to recurrence/regrowth of craniopharyngiomas. Clin Neurol Neurosurg 108:661-669, 2006

49. Van Effenterre R, Boch AL: Craniopharyngioma in adults and children: a study of 122 surgical cases. J Neurosurg 97:3-11, 2002

50. Weiner HL, Wisoff JH, Rosenberg ME, Kupersmith MJ, Cohen H, Zagzag D, et al: Craniopharyngiomas: a clinicopathological analysis of factors predictive of recurrence and functional outcome. Neurosurgery 35:1001-1011, 1994

51. Yamada S, Fukuhara N, Oyama K, Takeshita A, Takeuchi Y, Ito J, et al: Surgical outcome in 90 patients with craniopharyngioma: an evaluation of transsphenoidal surgery. World Neurosurg 74:320-330, 2010

52. Yang I, Sughrue ME, Rutkowski MJ, Kaur R, Ivan ME, Aranda D, et al: Craniopharyngioma: a comparison of tumor control with various treatment strategies. Neurosurg Focus 28(4):E5, 2010

53. Yaşargil MG, Curcic M, Kis M, Siegenthaler G, Teddy PJ, Roth P: Total removal of craniopharyngiomas. Approaches and long-term results in 144 patients. J Neurosurg 73:3-11, 1990

\section{Disclosure}

The authors report no conflict of interest concerning the materials or methods used in this study or the findings specified in this paper.

\section{Author Contributions}

Conception and design: Mamelak, Wu, Bonert, Carmichael. Acquisition of data: Mamelak, Jeswani, Wu, Carmichael, Chu, King. Analysis and interpretation of data: Mamelak, Jeswani, Nuño, Bonert, Black, Chu, King. Drafting the article: Mamelak, Jeswani, Bonert. Critically revising the article: Mamelak, Nuño, Black. Reviewed submitted version of manuscript: Mamelak, Jeswani, Nuño, Wu, Carmichael. Statistical analysis: Mamelak, Jeswani, Nuño. Administrative/technical/material support: Carmichael. Study supervision: Mamelak, Black.

\section{Correspondence}

Adam Mamelak, Department of Neurosurgery, Cedars-Sinai Medical Center, 127 S. San Vicente Blvd., A6600, Los Angeles, CA.email:mamelaka@cshs.org. 